American Journal of Pharmaceutical Education 2020; 84 (4) Article 7802.

\title{
COMMENTARY
}

\section{Cultivating a Vibrant and Thriving Elective Curriculum in Pharmacy Schools}

\author{
Helen D. Berlie, PharmD, ${ }^{\mathrm{a}, \mathrm{b}}$ Kristin K. Janke, PhD, ${ }^{\mathrm{c}}$ Candice L. Garwood, PharmD ${ }^{\mathrm{a}, \mathrm{d}}$ \\ ${ }^{a}$ Wayne State University, College of Pharmacy and Health Sciences, Detroit, Michigan \\ ${ }^{\mathrm{b}}$ Health Centers Detroit Medical Group, Detroit, Michigan \\ ${ }^{c}$ University of Minnesota, College of Pharmacy, Minneapolis, Minnesota \\ ${ }^{d}$ Harper University Hospital, Detroit Medical Center, Detroit, Michigan \\ Submitted August 1, 2019; accepted October 23, 2019; published April 2020.
}

\begin{abstract}
Elective courses are required in Doctor of Pharmacy (PharmD) curricula in the United States, but they may receive less attention than required courses in the core curriculum. Elective courses can serve as a platform for innovation in, experimentation with, and implementation of high-impact educational practices. However, these benefits may not always be realized or maximized. We advocate for an "elective curriculum" that is strategically designed and intentionally planned and managed. Students, faculty members, and administrators all play important roles in creating this curriculum. To ensure the curriculum is vibrant and thriving, attention is needed to: alignment with institutional missions, meeting the postgraduation needs of students and employers, enhancing faculty development and faculty experience, strengthening partnerships within the university and/or external entities, and moving the profession forward.
\end{abstract}

Keywords: pharmacy education, pharmacy curriculum, elective courses, curriculum management

Classroom-based core and elective courses make up the majority of the Doctor of Pharmacy (PharmD) program. Intentional planning of elective courses can elevate the pharmacy education experience. For the purpose of this paper, the terms "electives" and "elective courses" will be used in reference to electives completed prior to the advanced pharmacy practice experiences. Santee described the variety and quantity of elective courses, ${ }^{1}$ and many examples of elective courses are described in the literature. Elective courses offer benefits to students, faculty members, and the institution. For pharmacy students, electives create opportunities to explore career interests, deepen their knowledge in a specific disciplinary area, develop a focused skill set, and help them differentiate themselves from other pharmacy graduates. As such, electives are an important factor in a student's academic and professional development. Elective courses allow pharmacy educators to get to know students better, delve more deeply into topics, experiment with teaching methods, and share their expertise. Given their structure and flexibility, these courses may foster faculty job satisfaction. From an institution's perspective,

Corresponding Author: Candice L. Garwood, Wayne State University, College of Pharmacy and Health Sciences, 259 Mack Ave, Ste. 2190, Detroit, MI 48201. Tel: 313-577-1731. Email: cgarwood@wayne.edu. electives can help highlight the school's areas of emphasis, create additional opportunities for involvement of alumni and friends of the program, and promote teaching innovation.

Despite the benefits, elective courses may receive less administrative attention than core curriculum courses. They may come into existence solely based on faculty disciplinary focus, recondite interests, and willingness. They may continue over time based on an individual faculty member's enthusiasm and workload. If driven only by these criteria, electives may appear as random or isolated add-ons to the core curriculum. However, balancing the focus with student and institutional needs could more effectively maximize the educational experience for students. Elective courses could be clustered together into strategic sets that, when taken together, develop a depth of competency in specific areas for students.

\section{Intentional Planning of a Vibrant Elective "Curriculum"}

To maximize the benefits to students, faculty members, and the institution, electives must be intentionally planned and managed. Adopting a more strategic and attentive approach to electives may require significant discussion and debate. Ideally, electives are tightly aligned with the core curriculum, extending student knowledge and skills in tangible ways. They might even be designed to 


\section{American Journal of Pharmaceutical Education 2020; 84 (4) Article 7802.}

address curricular goals (eg, exercising problem-solving abilities) or shortcomings (eg, need for more motivational interviewing opportunities). Elective courses are also well positioned to further prepare students for current and future practice realities, helping to develop abilities that are desired in the workplace. In addition, electives can affirm the school's mission, making the school's priorities and commitment visible and "real."

Adopting a more deliberate approach to creating electives may require changes in administrative practices. Broader consultation with practice-based colleagues may identify emerging patient and health care system needs that require practitioner preparation, which an elective course could provide for students. Rather than waiting to see which electives faculty members are interested in offering, school administrators may need to request that faculty members teach specific elective courses to address priority areas. In order to increase the impact of elective courses on students' future practice contributions, existing electives may require thoughtful review and revision. To ensure sustainability and foster creativity in teaching methods and approach, faculty members may need to form and nurture teaching teams. To increase the authenticity, practicality, and utility of elective course learning activities, administrators may need to seek external partnerships. For responsive and sustainable electives, schools may need to cultivate the environment for them to exist.

Ideally, elective courses in the PharmD program could be considered a curriculum within the curriculum. Approaching electives as a curriculum (or program) encourages the development of comprehensive goals. Electives may already have stated learning related goals, such as providing "hands on" learning opportunities. However, there may be other goals. For example, the elective program may have a goal of enhancing the student experience. This might be achieved by designing courses that emphasize the development of meaningful faculty-student connections or electives that provide formalized opportunities for individualized advising or mentoring. Elective curricula may advance institutional or school goals, such as expanding impact through community engagement or mobilizing focused efforts in rural or urban health. We encourage schools to consider the role of electives in achieving specific learning, teaching, student experience, faculty development, practice development, and community or institutional goals, among other things.

As the curriculum is formulated, the collection of elective courses can be evaluated. During evaluation, questions that should be asked include: What are the substantive skills that students are building? What assurances do we have that students are developing these abilities? Is the collection of elective course options meeting students' interests and advancing student career aspirations and opportunities? How can courses be effectively linked with field work or introductory or advanced practice experiences? Sequences of courses can take shape and help to build knowledge and skills, as well as create areas of focus. Combined with experiential education, an elective course curriculum can facilitate officially designated tracks, pathways, concentrations, certificate programs, or dual degrees, ${ }^{2}$ the attainment of which may help students to distinguish themselves from other graduates and may be attractive to residency programs, graduate programs, and/or employers.

Class sizes are often smaller in elective courses than required coursework, further enabling creativity in the course design. These courses are an ideal setting in which to implement high-impact educational practices. According to Brownell and Swanner, high-impact practices have "unusually positive effects on student engagement in educationally purposive behavior."3 High-impact practices include: collaborative assignments and projects, student-faculty research, intensive writing, service learning, community-based learning, study abroad, ePortfolios, capstone projects, and learning communities. ${ }^{4}$ There are eight conditions, or key elements, that underpin the success of high-impact practices: performance expectations set at appropriately high levels; significant investment of time and effort by students over an extended period of time; interactions with faculty members and peers about substantive matters; experiences with diversity; frequent, timely, and constructive feedback; periodic, structured opportunities to reflect and integrate learning; opportunities to discover relevance of learning through real-world applications; and public demonstration of competence. ${ }^{5}$ When working to increase the impact of elective courses, these key conditions, as well as the incorporation of quality high-impact practices, should be considered during the design phase.

Furthermore, pharmacy schools should strive for an elective curriculum that is vibrant. Merriam-Webster Dictionary defines vibrant as: "having or showing great life, activity and energy." 6 What roles do students, faculty members, and administrators play in creating a vibrant elective curriculum? The following sections explore the roles of each group.

\section{Partnering with Students and Providing a Sandbox for Faculty}

Through well-designed elective courses, students can actively participate, directly apply skills, enhance personal and professional development, and increase their 


\section{American Journal of Pharmaceutical Education 2020; 84 (4) Article 7802.}

confidence. The pharmacy job market and postgraduate training positions are becoming increasingly competitive as the supply and demand for pharmacists has shifted. ${ }^{7,8}$ Optimally, the elective curriculum will: provide students with well-developed workforce preparation, ignite positive discussions during job interviews, and aid in students attaining their placement of choice upon graduation.

Creation of systems that enable students to make meaningful decisions about electives can benefit the development of such an environment. Holding an information program or orientation to elective course options can encourage informed decisions, make processes and policies clear, and support a culture of engagement with the elective curriculum among students. Academic advising should guide students in identifying individual career goals, promote exploration of professional interests, and foster thoughtful course planning. Advising is a key component in maximizing student success within the elective curriculum.

Ideally, faculty members will be inspired to offer elective courses, and doing so will inspire their creativity. Electives are a perfect medium through which faculty members can be innovative, inventive, and even rejuvenated. When focused on invigorating and dynamic content, electives can lead to high energy and high engagement for both faculty members and students. Additionally, electives can change and adapt in ways that may not be possible in larger core curriculum courses. Thus, an elective course can serve as a platform where new techniques and approaches can be conceived and tested. The elective curriculum can be a "sandbox" for curricular innovation, where ideas are tried, evaluated, and if successful, scaled up to become part of the core curriculum. Electives also present opportunities to engage in the scholarship of teaching and learning by creating, evaluating, and disseminating the experience. Furthermore, elective courses can foster collaborations and teaching partnerships that have the potential to expand outside of the classroom.

Collaboration is an effective way to maximize strengths, increase the landscape for creativity, balance workload, and enhance course stability. Areas of expertise and strengths within departments, programs, and institutions should be considered. Collaborators can be pharmacy faculty colleagues, pharmacy residents, graduate students, adjunct faculty members, and even faculty members from other departments. Collaborators can serve as instructors, co-coordinators, or coordinators for elective courses. Sharing expertise and distributing workload can be advantageous to offering a healthy slate of electives. Furthermore, if there are enough programmatic strengths or instructors with common interests, elective sequences or concentrations can be developed. Topics for elective concentrations might include research, ${ }^{9}$ leadership, ${ }^{10}$ academia, ${ }^{11}$ or specialized clinical focus areas. ${ }^{12}$ These concentrations may involve partnering with other health professions for interprofessional design and delivery. They can also include partnering with experiential education to provide additional venues for students to practice their new skills.

As faculty members contemplate offering elective courses, they should consider the potential for: teaching innovation, increased job satisfaction, career advancement, and relationship building with students and colleagues. Ultimately, creating a vibrant elective curriculum requires adequate support from curriculum committees as well as administration.

\section{A Strategic Leadership Challenge}

Pharmacy schools should strive toward establishing a thriving elective curriculum. Merriam-Webster Dictionary describes thriving as "characterized by success or prosperity." 13 To deliver an elective curriculum, administrators must manage operations related to electives, such as room scheduling and budgets. However, to thrive, administrators must also establish direction and lead the strategy for building a vibrant elective curriculum. With their mission responsibilities, directors and deans of student services and curriculum are intimately aware of the school's ambitions and its progress toward its goals. As a result, they are well-positioned for helping to grow and situate electives that align with mission and priority areas. For example, a school that is emphasizing patient-centered care may invest in developing a health coaching course that is available to both students and preceptors. Another example is a school that is dedicated to practice expansion might develop elective courses in high potential areas for increased pharmacist involvement (eg, mental health, quality improvement teams) and/or electives that provide relevant skills (eg, building a practice, entrepreneurship). These courses would reflect their commitment, help them to connect with external partners active in these areas, and build faculty and student abilities, which could then be used to enhance experiential sites and future practices.

Thriving elective courses should draw from areas of faculty expertise and excellence; however, they should not be dependent upon a single individual. To thrive, there should be a critical mass of faculty members that can work together in developing and delivering quality courses, covering when there are leaves, faculty changes, etc. In order for courses to be sustainable and responsive, administrators can aid in capacity building and cultivating strong teaching teams, which involves working to develop both individuals and groups of faculty members. 


\section{American Journal of Pharmaceutical Education 2020; 84 (4) Article 7802.}

Table 1. Considerations for Creating a Vibrant and Thriving Elective Curriculum

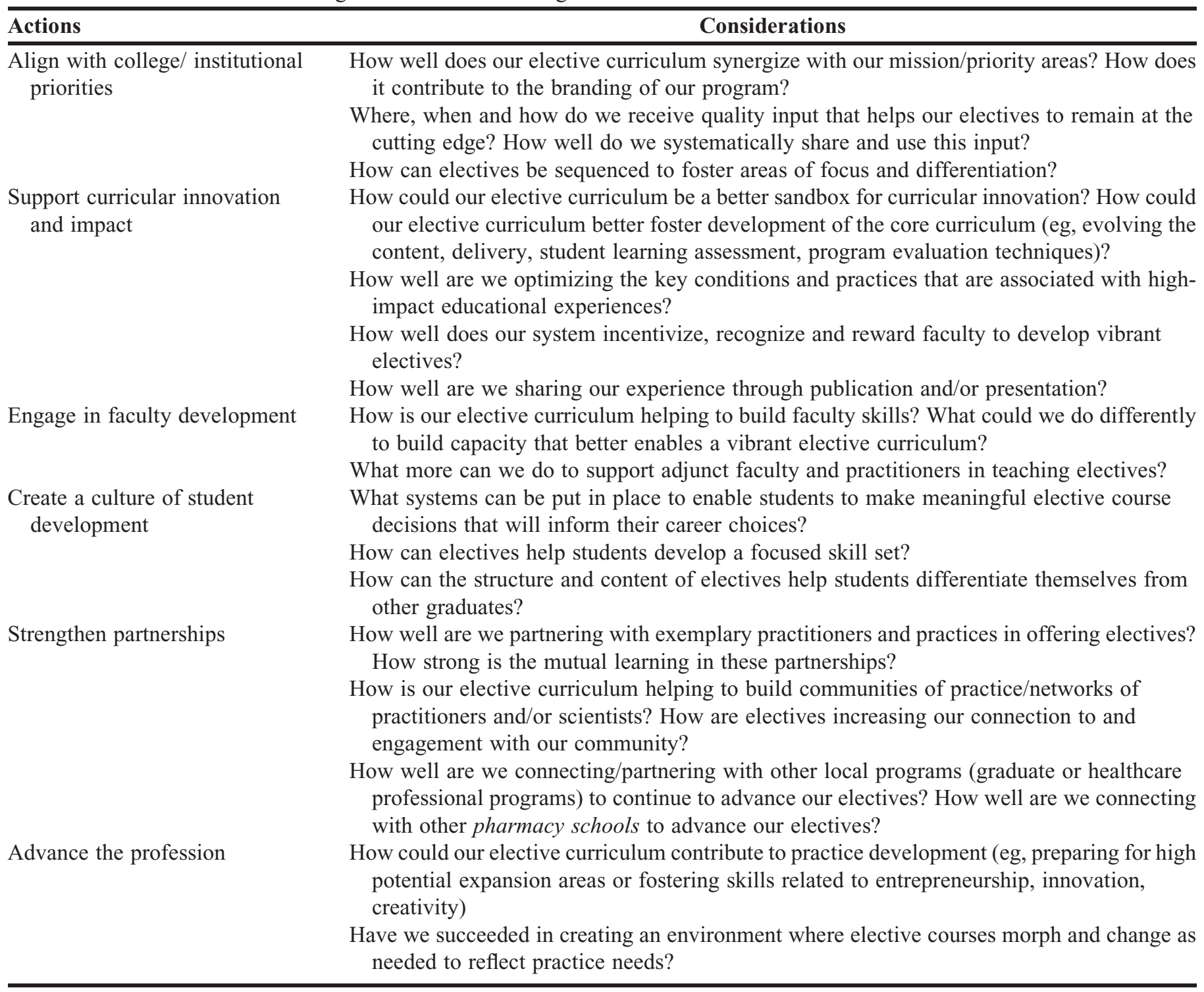

Administrators can also assist in active workload management by aiding faculty members in rebalancing teaching, research, and service commitments as additional teaching is added.

Administrators also play a role in refining and reformulating the elective curriculum. When there is significant institutional commitment to an area, faculty capacity, and student interest, administrators can assist in orchestrating groupings of electives, eg, series, track, concentration. This likely involves establishing partnerships and/or networks within the university or with external practitioners or organizations. Practitioner support may be particularly important when field trips, shadowing, practice-based projects, and mentoring and advising are components of the electives. Finally, administrators can guide policy and system development. These policies should aid students in the selection of elective courses, maintain course enrollment, and support the continued success of the elective curriculum. These policies should also include incentives and recognition for faculty members to create high-quality electives, resources to support delivery, and training for adjunct faculty members and practitioners that may wish to teach. Table 1 includes considerations that can assist pharmacy schools with some reflective discussions necessary for creating a vibrant and thriving elective curriculum.

\section{SUMMARY}

To create a vibrant and thriving elective curriculum, schools must leverage their areas of excellence and create systems and policies that facilitate success. In turn, an environment of innovation and experimentation should 


\section{American Journal of Pharmaceutical Education 2020; 84 (4) Article 7802.}

be fostered. This includes mechanisms to identify a need for new electives to be developed. Course review and program evaluation can help strengthen the ties between electives and the core curriculum and/or experiential curriculum. As the elective curriculum evolves, flourishing teaching strategies, learning activities and assessments can be scaled up and used in the core curriculum. Ultimately, a vibrant and thriving elective curriculum will enable our students to develop deeper skillsets, differentiate themselves upon graduation, and contribute to moving the profession forward.

\section{REFERENCES}

1. Santee J, Mead T, Garavalia L, Fincham J. Variety and quantity of professional electives. Am J Pharm Educ. 2012;76(10):Article 195.

2. Vuernick EL, Josefiak KF, Spooner JJ, Kennedy D. Non-doctoral and dual degree offerings in US pharmacy schools. Am J Pharm Educ. 2019;83(7):Article 6917.

3. Brownell JE, Swanner LE. Five High-Impact Practices: Research on Learning Outcomes, Completion, and Quality. Washington, DC: Association of American Colleges and Universities; 2010.

4. Kuh GD. High-Impact Educational Practices: An Overview. American Association of Colleges and Universities, 2008. https:// www.aacu.org/leap/hips. Accessed April 14, 2020.
5. Kuh GD, O'Donnell K. Ensuring Quality and Taking High-Impact Practices to Scale. Washington, DC: Association of American Colleges and Universities, 2013.

6. Definition of Vibrant. Merriam-Webster Dictionary. https://www. merriam-webster.com/dictionary/vibrant. Accessed April 14, 2020.

7. Schneider PJ, Pedersen CA, Ganio MC, Scheckelhoff DJ. ASHP national survey of pharmacy practice in hospital settings: Workforce 2018. Am J Health Syst Pharm. 2019;76:1127-1142.

8. Lebovitz L, Eddington ND. Trends in the pharmacist workforce and pharmacy education. Am J Pharm Educ. 2019;83(1):Article 7051.

9. Surratt CK, Drennen JK, Bricker JD. The "research track" concentration, a new PharmD elective option. Am J Pharm Educ. 2005;69(5):Article 90.

10. Janke KK, Nelson MH, Bzowyckyj AS, et al. Deliberate integration of student leadership development in doctor of pharmacy programs. Am J Pharm Educ. 2016;80(1):Article 2.

11. Poirier TI, Santanello C. Impact of a pharmacy education concentration on students' teaching knowledge and attitudes. Am J Pharm Educ. 2010;74(2):Article 23.

12. Ryan GJ, Chesnut R, Odegard PS, Dye JT, Jia H, Johnson JF. The impact of diabetes concentration programs on pharmacy graduates' provision of diabetes care services. Am J Pharm Educ.

2011;75(6):Article 112.

13. Definition of Thriving. Merriam-Webster Dictionary. https:// www.merriam-webster.com/dictionary/thriving. April 14, 2020. 